\title{
Automatic Speed Control of Motor via WAD Technique for Prevention of Faults in Motor
}

\author{
R. Kabilan ${ }^{1}$, G. Selvakumar ${ }^{2}$ \\ ${ }^{1}$ Sathyabama University, India \\ ${ }^{2}$ Muthayammal Engineering College, India
}

\begin{tabular}{l}
\hline \hline Article Info \\
\hline Article history: \\
Received Jan 9, 2018 \\
Revised Jan 23, 2018 \\
Accepted Feb 7, 2018 \\
\hline
\end{tabular}

\section{Keyword:}

MEMS

Neuro-Fuzzy

WAD

\begin{abstract}
Many technologies are introduced in monitoring the fault occurrence in the electric motors used in industrial applications. Sound Accusation, current signature analysis, and vibration based motor fault detection systems are widely used in present years. From all these methods analyzing the motor vibration pattern produces more accuracy in finding an occurrence of different faults in the electric motor. The frequency of vibration generated by the MEMS vibration sensor differs for rotor, stator and bearing faults. The signal generated is analyzed using three important techniques namely wavelet analysis, Dyadic Transformation, and Adaptive Neuro-Fuzzy Inference System(WAD Technique). Hardware with ARM microcontroller and ADXL MEMS vibration sensor was used to perform signal acquisition, and the generated signal is processed using the MATLAB software, and the speed of the motor is controlled based on the processed result. The performance of the system with all three algorithms was recorded, and the efficiency of the system is compared.
\end{abstract}

Copyright $@ 2018$ Institute of Advanced Engineering and Science. All rights reserved.

\section{Corresponding Author:}

R. Kabilan,

Research Scholar, Sathyabama University,

Rajiv Gandhi Salai, Jeppiaar Nagar, Chennai, Tamil Nadu 600119, India,

Email: kabi.r@rediffmail.com

\section{INTRODUCTION}

Practically all industrial development around us is refined by an electric motor. Electric motors are used to convert energy from one form to another. It converts electrical energy into mechanical motion, which helps to drive several industrial machines. Any faults generated in electric motors cause much loss in industrial development. Motor faults lead to a shutdown of complete generation in industries. Motors developed in current year's needs only minimum maintenance, to ensure the efficiency of its operation. The causes and classification of electric motor failure are an important criteria in fault management system because it's strong effect on the dependability of industrial process. And the faults in electric motor are not occurred arbitrarily or at once. The fault generation may occur due to chronic and progressive form, which leads to reduce the torque, generate high temperatures and vibration in the motor.

The study on electric motor failure creates a trend of developing online or offline methods to identify and measure the occurrence of the failure in motors. The fault in the motor was defined as inefficiency to perform a particular work. The cause of failures was listed as

a. Underlying weakness of material and structure

b. Improper use of the motor

c. Gradual failure due to wear, tear and fatigue due to stress and corrosion. 
The study about motor failures provides results that early identification of motor fault helps in maintaining the reliability of the motor. The source of occurrence of the fault in the motor was classified as internal source and external source.

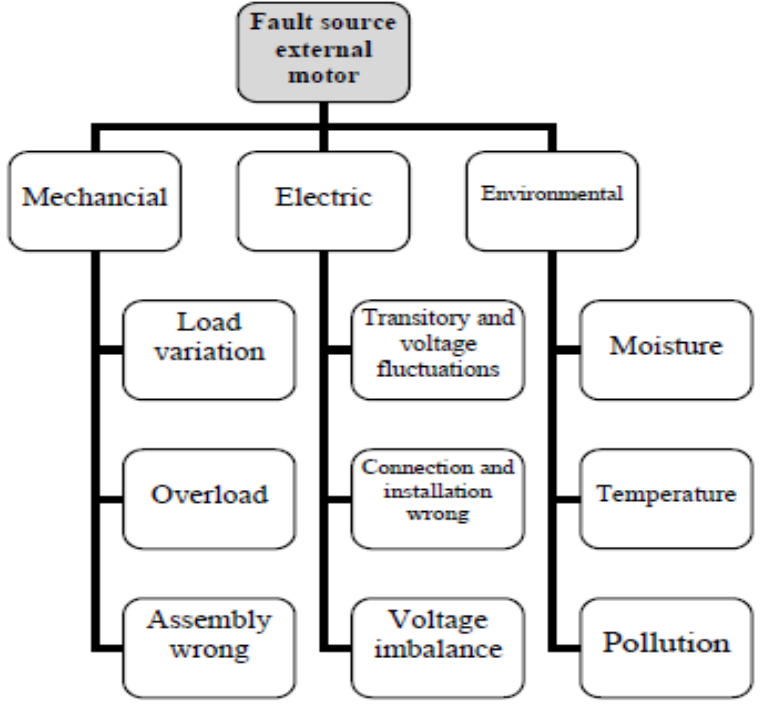

Figure 1 a) Faults due to external source

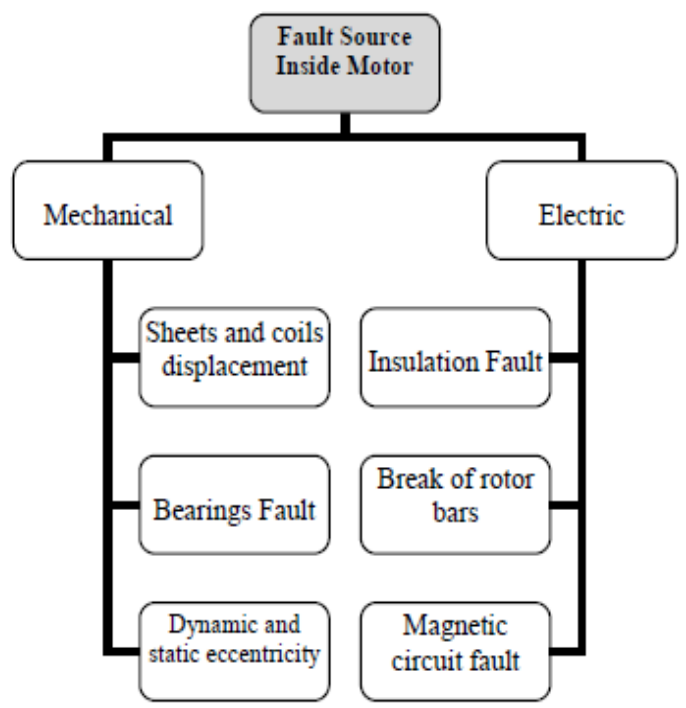

Figure 1 b) Faults due to internal source

Failures due to the internal source are mainly due to decline in quality of the materials in the motor and manufacturing faults. But the failures due to external source were due to environmental change, overload and improper handling of the motor. The load and speed management for electric motors was introduced to overcome the failure. Controlling the peed of the electric motor based on the applied load and power provides more safety for rotors and stators from damage.

\section{RELATED WORK}

Broken rotor bar fault is analyzed using strain measurement by running the four pole induction motor in $70 \%$ and $100 \%$ payload condition. A Bragg grating strain sensor is placed between the stator teeth's of the motor. The output spectrum values of strain sensor were measured continuously. If any fault occurs in the rotor the changes is measured using sensors output spectrum. The frequency of changes in the sensor output depends on the motor slip. Different power sources are provided to analyze the effect of the rotor bar of the bar. Electric grid and the variable frequency drives are used as different power source for the motor. The output spectrum frequency was analyzed on two different regions, they are rotor frequency and the twice amount of supply frequency. The broken rotor bar fault also can be analyzed using harmonics disturbance in the line voltage of the motor. [1]

Artificial neural network based fault identification is used to identify and classify the bearing fault in induction motor. The induction motor was directly powered through power grid. The current signature analysis is performed by applying unbalanced input voltage and load. The results are collected in time domain and parameters like voltage and current consumption of motor is collected based on the half cycle of the voltage power grid. Digital signal processor is used to perform artificial neural network on collected motor parameters. [2]

DC input current is measured to analyze the fault in motor shaft due to torque disturbance in permanent magnet synchronize motor. The disturbance in the input DC current of inverter due to improper torque is analyzed using MATLAB simulator. Spectra test rig is developed to identify the fault developed in the gear box and other components of the motor. [3]

Recorded signals from faulty motor were processed using spectrum analysis to demodulate information about the faulty frequencies. Signal Processing techniques like Fast Fourier transform and filters are involved to perform envelop analysis to extract fault signal from the original recorded signal from motor. Empirical demodulation technique is used to analyze the time domain data to extract information about the fault signals. [4] 
Signal based fault identification system provides more comfortable to identify the fault present in the electric motor. The motor signals are applied for signal processing technique to split the signals into multiple frequency forms. Faulty frequency was extracted using spectrum analyzing techniques. Algebraic summation operation is introduced to analyze the signals of healthy motors. ASO operates based on stationary wavelet transformation. The redundancy generated at decomposition phase is conserved to amplify the error generating frequencies in the recorded vibration signal of electric motor. [5]

Fault detection in non-stationary motors is widely performed in industries. Diagnosing the fault in inverter feed motors is a major concern over the line feed motors. Signal processing techniques are proposed to identify the fault signature from the recorded signal in time and frequency domain. Fault detection in inverter feed induction motor is performed by considering two different inverter feed induction motors with two different faults in the motor. The fault diagnosis is performed in transient states. Fast Fourier transform and short time Fourier transform are used to identify the broken bar fault and mixed eccentricity in the inverter feed induction motor. [6]

Open circuit faults generated in power convertors will affect the performance of the electric motor which leads to fault in motor by running the motor in unbalanced state. If the fault occurred in the power converter is not attended then it leads to catastrophic failure in the electric motor and also in complete motor drive circuit. Current sensor and the asymmetric half bridge converter are used to identify the open circuit fault in the motor drive circuit. Individual bus positions are defined to analyze single phase and two phase faults. Fast Fourier transform and Blackman window techniques are used to process the signals with and without open circuit fault. The open circuit fault is identified by comparing the bus current and the rotor position of the electric motor. [7]

Faults like broken ring and rotor bar fault are common in induction motors. The motors with ac grid supply were widely used to measure the fault in rotor and stator component. Here the induction motor feed with inverter power source is considered. The faults generated in the rotor and stator was measured by harmonic level in the input inverter current source. The harmonic level is measured in low load, high load, normal and transient operation. This method provides higher accuracy rate in open loop variable frequency motors. [8]

Stator current signature analysis is efficient method in predicting the fault in the induction motor. Current signature analysis is used to identify faults like stator, rotor and bearing faults in induction motors. This method records the motor current and voltage in the normal running condition and calculates autocorrelation for these values. These auto correlated values are used as threshold to differentiate the fault signals from the normal stator current signal. Current signal analysis method can affected by quality of the voltage source, so the recorded correlated value should be filtered automatically based on the quality of the voltage source to improve the detection rate of the current signature method. [9]

Kernel density estimation is used to convert the 3 phase current dimension to 2 dimensional spaces. It performs probability distribution function to differentiate faulty signals from the normal signals of the induction motor. The probability distribution function is used to classify the type of fault generated in the motor. To differentiate the fault signal, kullback-leibler divergence is used over the probability distribution function to provide automatic fault identification in motors. The performance of the kernel density estimation was improved using fast Gaussian transform and point reduction procedure. The improved method was used to perform IOT monitoring in motor fault identification system. [10]

Region selection and space vector pulse width modulation (SVPWM) apply for diode clamped voltage source inverter. The technique applies for open loop operation in inverter fed induction motor drive. The performance of SVPWM compare with Conventional BCPWM technique [11]. A fuzzy single neuron PID applies to improve performance of brushless DC motor. The design concept is two-fold. Initially Genetic algorithm applies to find optimum parameters for single neuron PID. Furthermore, the results from genetic algorithm apply to adjust weights for SNPID. The performance of conventional fuzzy logic control compare with Fuzzy single neuron PID [12].

Sequential rotor detection with PWM applies to run motor with power produced by solar PV modules. The stator energising and rotor control use to vary speed of motor. Digital signal control locks PWM signal width to stabilize PV modules operation [13]. FOPID technique applies for boost converter fed DC motor drive. The FOPID improves the performance of three-stage ILBC DC motor drive system. The closed loop ILBCDCM system performance compare with FOPID technique [14].

\section{RESEARCH METHODOLOGY:}

\subsection{Wavelet Analysis}

Wavelet transformation was applied in several applications to analyze the recorded analog signal in detail. Due to the peculiar characteristic of wavelet transformation, it has been used for analyzing high- 
frequency signals. The wavelet transform method is more efficient in analyzing the transient and start-up current signature of the electric motor. The wavelet transformation provides more facilities than the traditional Fourier transform. It helps to decompose several layers of the signal to analyze the fault signal more efficiently. The recorded signal was segmented and multiplied with functions with wavelets, similar to the windowing technique used in Fourier transform. The continuous wavelet transformation was defined using

$\mathrm{W}(\mathrm{a}, \mathrm{b})=\frac{1}{\sqrt{a}} \int_{-\infty}^{\infty} x(t) \varphi\left(\frac{(t-b)}{a} d t\right)$

\subsection{Dyadic Transformation:}

The dyadic transformation decomposes the input signal into higher and lower frequency signals which help to generate detailed and approximate information about the recorded signal. The peak values of the higher and lower frequency signal were generated from the decomposed signal. Dyadic transformation is performed by selecting a mother wavelet function and dilates it with the power of two.

Let $\varphi$ be the mother wavelet function the dyadic dilation function at stage $\mathrm{j}$ is generated as

$\varphi \_\left(2^{\wedge} \mathrm{j}\right)(\mathrm{x})=\left[1 / 2^{\wedge} \mathrm{j}\right] \varphi\left[\mathrm{x} / 2^{\wedge} \mathrm{j}\right]$

The transform function $\mathrm{f}(\mathrm{x})$ of dyadic scale $2^{j}$ at area $\mathrm{x}$ is defined as follow

$W_{2^{j}} \mathrm{f}(\mathrm{x})=\mathrm{f} * \varphi_{2^{j}}(\mathrm{x})=\int f(t) * \varphi_{2^{j}}(\mathrm{x}-\mathrm{t}) \mathrm{dt}$

From the above equations, the dyadic wavelet transform is generated as

Df $=\left(W_{2^{j}} f(x)\right)_{j \in Z}$

\subsection{Adaptive Neuro-Fuzzy Inference System:}

ANFIS is developed based on the fuzzy inference logic with five layer feedback system. Using this five layer network the ANFIS system provides the advantage like learning system in the neural network and inference model in fuzzy logic. ANFIS system utilizes the advantages of both fuzzy and neural network which makes the method more efficient than traditional wavelet analysis method. The structure of two inputs, two rules, and one output ANFIS system was designed to analyze the input signal to extract approximate data from it.

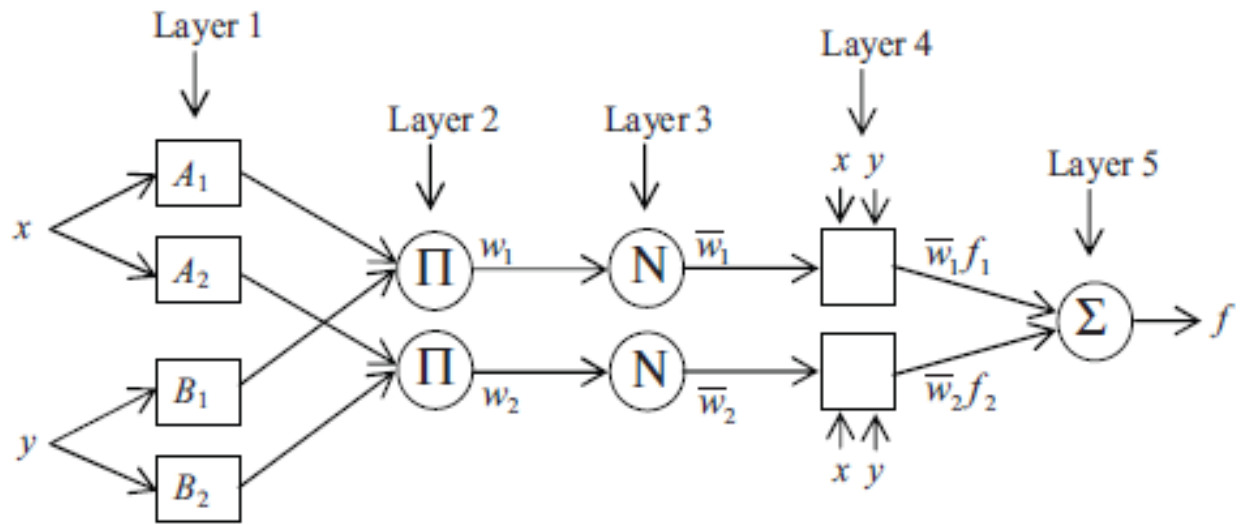

Figure 3. ANFIS System model 


\section{RESULTS AND DISCUSSION}

An Embedded system has been designed using MEMS vibration sensor and ARM cortex m4 controller. The sensor signal was captured using DAQ card, and the recorded signal is analyzed using MATLAB software. Three different signal analyzing algorithms namely wavelet transformation, Dyadic transformation, and Adaptive Neuro-Fuzzy Inference System is implemented, and the performance of the system was compared with simulation output results. The signals have been recorded in, with load and without load conditions and the recorded signals are processed to find the high and low values in the amplitude of the signal using the signal analyzing an algorithm to identify the fault in the electric motor.

\subsection{Wavelet Transformation:}

Figure 4 displays the results of wavelet transformation under the fault condition. The amplitudes of each parameter display some error signals present in it. By comparing the outputs of the normal and fault signals, the output explains the severity of fault in the electric motor.

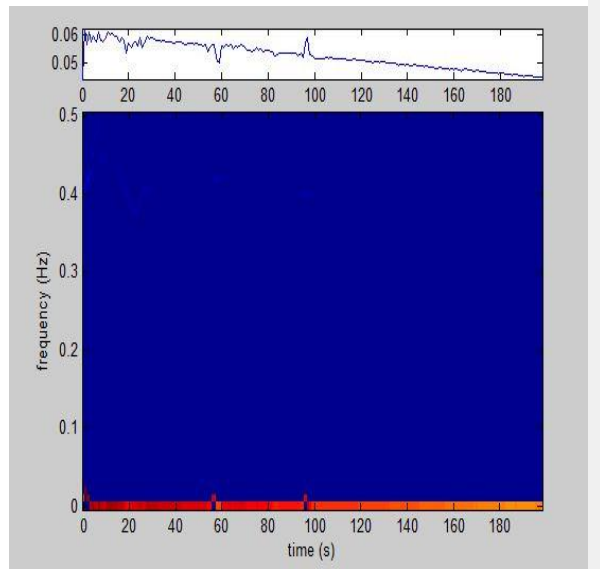

(a)

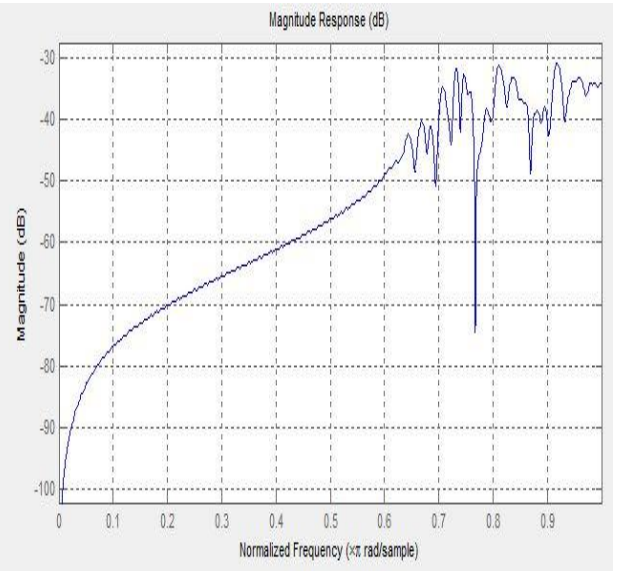

(b)

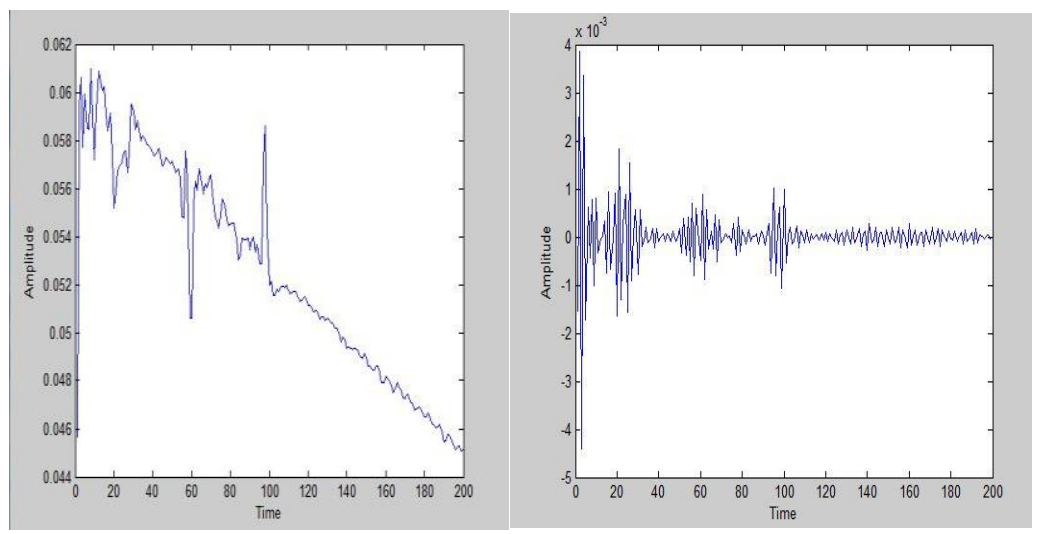

(c)

(d)

Figure.4.(a) vibration of the frequency ratio concerning the time in second. (b): The comparison of magnitude concerning normal frequency. (c): The comparison of Amplitude concerning time in the first set region. (d) The comparison of Amplitude concerning time in the second set region.

\subsection{Dyadic Transformation:}

The transient effect and the imbalance load have been introduced to the normal motor, and the changes in the output of the system are represented in Figure 5. The output shows that the occurrence of higher peak values was more frequent. The difference in the outputs of the motor with and without fault was distinguishable using dyadic transformation. 


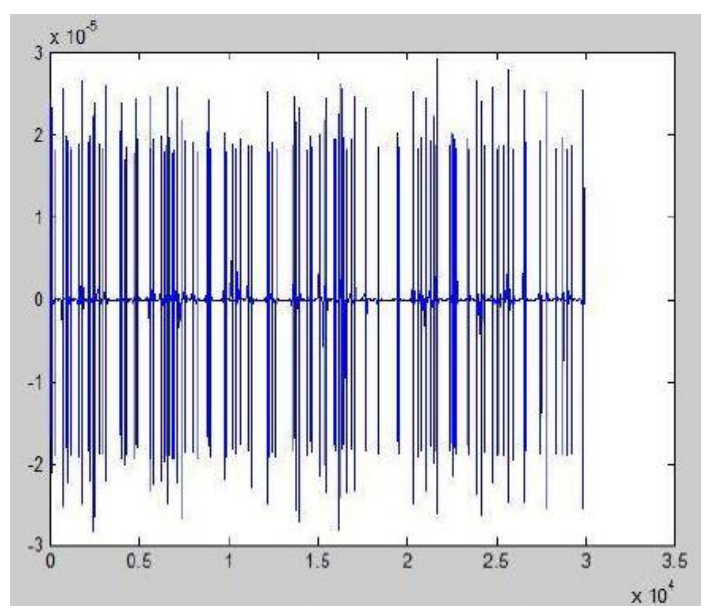

Figure 5. Output of dyadic transformation for with fault condition.

\subsection{ANFIS System:}

The sensor data is collected from the faulty electric motor. The Figure 6 and 7 shows the train and test data for the faulty signal.
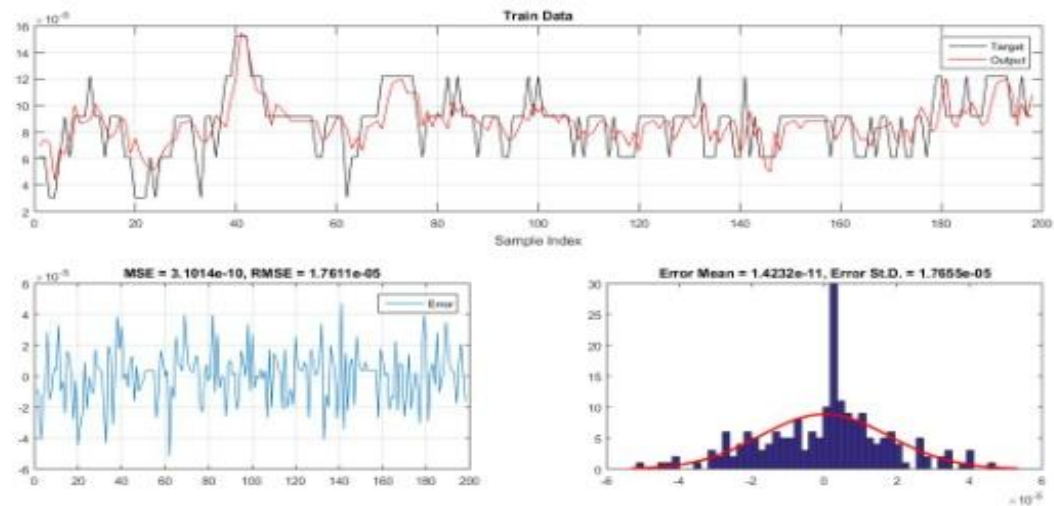

Figure 6. Train data at fault condition
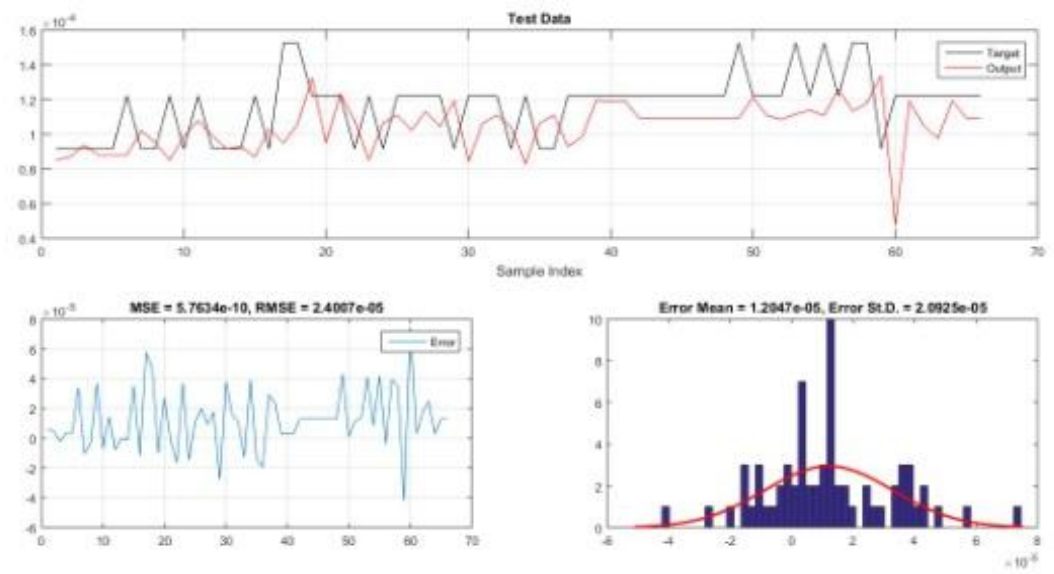

Figure 7. Test data at fault condition 
The Figure 8 displays MSE and mean error rate for the complete recorded faulty signal. The values measured, MSE is achieved as $3.76 e^{-10}$, RMSE value as $1.9 e^{-5}$, Error mean as $3.0117 e^{-6}$ and standard deviation of $1.921 e^{-5}$

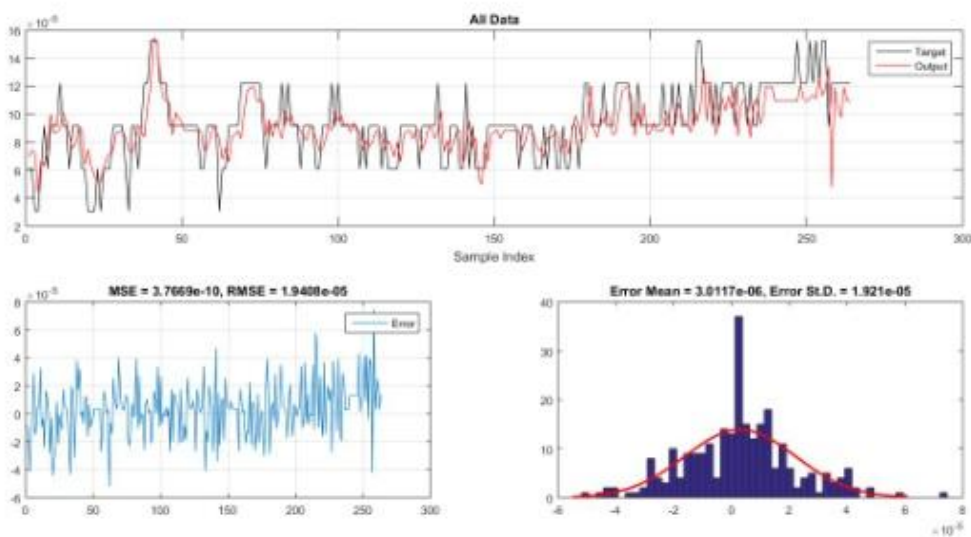

Figure 8. All data at fault condition

The MSE and Error mean values shows the difference in values for error signals and normal signals collected through vibration sensor from the electric motor. The accuracy of identification of fault is higher when compared to other existing techniques.

\section{CONCLUSION}

A closed loop analysis for motor fault detection system was introduced in this work. The fault in electric motors affects the performance of the complete system in industries. Predicting and identification of the fault in the electric motor are main challenges in the recent research area. Three methods namely Wavelet analysis, Dyadic Transformation and ANFIS system have been developed and studied the performance of the individual system. The results generated shows that the ANFIS system developed for analyzing motor fault generates more accurate results than compared to other techniques such as wavelet and dyadic transform based approach. The accuracy of the fault detection by ANFIS system is improved by $30 \%-40 \%$ higher than the other two methods.

\section{REFERENCES}

[1] K. M. Sousa, I. B. V. da Costa, E. S. Maciel, J. E. Rocha, C. Martelli, and J. C. C. da Silva, "Broken Bar Fault Detection in Induction Motor by Using Optical Fiber Strain Sensors," IEEE Sens. J., vol. 17, no. 12, pp. 3669-3676, 2017.

[2] W. S. Gongora, H. V. D. Silva, A. Goedtel, W. F. Godoy, and S. A. O. Silva, "Neural Approach for Bearing Fault Detection in Three Phase Induction Motors," IEEE Lat. Am. Trans., vol. 14, no. 3, pp. 594-600, 2013.

[3] J. Li, M. Sumner, H. Zhang, and J. Arellano-Padilla, "Fault detection for PMSM motor drive systems by monitoring inverter input currents," CES Trans. Electr. Mach. Syst., vol. 1, no. 2, pp. 174-179, 2017.

[4] F. B. Batista, P. C. M. Lamim Filho, R. Pederiva, and V. A. D. Silva, "An Empirical Demodulation for Electrical Fault Detection in Induction Motors," IEEE Trans. Instrum. Meas., vol. 65, no. 3, pp. 559-569, 2016.

[5] D. Bayram and S. Eker, "Redundancy-Based Predictive Fault Detection on Electric Motors by Stationary Wavelet Transform," Ieee Trans. Ind. Appl., vol. 53, no. 3, pp. 20-30, 2017.

[6] O. Duque-perez and J. Pons-llinares, "A Comparison of Techniques for Fault Detection in Inverter-Fed Induction Motors in Transient Regime," Ieee Trans. Ind. Appl., vol. 5, no. c, pp. 1-15, 2017.

[7] C. Gan, J. Wu, S. Yang, Y. Hu, W. Cao, and J. Si, "Fault diagnosis scheme for open-circuit faults in switched reluctance motor drives using fast Fourier transform algorithm with bus current detection," IET Power Electron., vol. 9, no. 1, pp. 20-30, 2016.

[8] I. P. Georgakopoulos, E. D. Mitronikas, and A. N. Safacas, "Detection of induction motor faults in inverter drives using inverter input current analysis," IEEE Trans. Ind. Electron., vol. 58, no. 9, pp. 4365-4373, 2011.

[9] T. Ghanbari, "Autocorrelation function-based technique for stator turn-fault detection of induction motor," IET Sci. Meas. Technol., vol. 10, no. 2, pp. 100-110, 2015.

[10] A. Giantomassi, F. Ferracuti, S. Iarlori, G. Ippoliti, and S. Longhi, "Electric motor fault detection and diagnosis by 
kernel density estimation and kullback-leibler divergence based on stator current measurements," IEEE Trans. Ind. Electron., vol. 62, no. 3, pp. 1770-1780, 2015.

[11] Nunsavath Susheela, "Performance Analysis of FPGA based Diode Clamped Multilevel Inverter Fed Induction Motor Drive using Phase Opposition Disposition Multicarrier Based Modulation Strategy" International journal of power electronics and drive systems, vol. 8, no.4.

[12] M.A. Abdel Ghany, Mohamed A. Shamseldin, A.M. Abdel Ghany, "A Novel Fuzzy Self Tuning Technique of Single Neuron PID Controller for Brushless DC Motor" International journal of power electronics and drive systems, vol.8, no.4.

[13] Slamet Riyadi, "Digital Control for a PV Powered BLDC Motor" International journal of power electronics and drive systems, vol.8, no.4.

[14] Bharathi M.L, "FOPID Controlled Three Stage Interleaved Boost Converter Fed DC Motor Drive" International journal of power electronics and drive systems, vol. 8 , no. 4 